\title{
Two Failed Replications of the Watching Eyes Effect
}

\author{
Keisuke Matsugasaki ${ }^{1}$, Wakana Tsukamoto ${ }^{2}$ and \\ Yohsuke Ohtsubo ${ }^{1, *}$ \\ 'Department of Psychology, Graduate School of Humanities, Kobe Univer- \\ sity, Kobe, 657-8501, Japan. \\ ${ }^{2}$ Faculty of Letters, Department of Psychology, Kobe University, Kobe, \\ 657-8501, Japan. \\ "Author for correspondence (yohtsubo@1it.kobe-u.ac.jp)
}

The watching eyes effect refers to the phenomenon that people behave more altruistically than usual when an eye-image is present in their environment. In this paper, we report two failed replications of the watching eyes effect. In both Studies 1 and 2, participants decided how many coins out of a seven coin endowment (each coin worth 100 Japanese yen) to allocate to a subsequent participant, under the assumption that the prior participant may have left them some coins. In Study 1, participants anonymously made their allocation decision while seated in front of a poster depicting either an eye-image or a geometric pattern. In Study 2, to increase the saliency of the watching eyes, participants were instructed to place the coins in envelopes (one for self and one for the subsequent participant) printed with either an eye-image or a geometric pattern. In both Studies 1 and 2 , the number of coins that participants allocated to subsequent participants did not significantly differ between the eye-image and control conditions. Moreover, the proportion of participants who allocated at least one coin to subsequent participants was not significantly different across the two conditions. In our studies, altruism was not increased by watching eyes.

\section{Keywords}

watching eyes effect, dictator game, replication

\section{Introduction}

People behave altruistically toward unrelated strangers. One evolutionary explanation for this type of cooperation is indirect reciprocity (Nowak \& Sigmund, 2005). Indirect reciprocity refers to a reputation-based mechanism of cooperation: People help other people who have a good reputation, and a good reputation is obtained by helping other people. Under a system of indirect reciprocity, a concern for maintaining a "good" reputation naturally arises. Empirical evidence shows that people do indeed behave more cooperatively in public settings, where their behaviors are known by others, than in private settings (Engelmann \& Fischbacher, 2009; Simpson \& Willer, 2008). The effect of reputational concern is so strong that even subtle cues of someone's presence (e.g., an image of eyes) seem to be sufficient to incline people to behave more cooperatively (e.g., Bateson, Nettle, \& Roberts, 2006; Haley \& Fessler, 2005; Oda, Niwa, Honma, \& Hiraishi, 2011). In this article, we refer to this phenomenon as the "watching eyes effect" (Nettle et al., 2013).

Despite many studies that report successful replications of the watching eyes effect, a growing number of studies report their failure to replicate it (e.g., Fehr \& Schneider, 2010; Raihani \& Bshary, 2012; Tane \& Takezawa, 2011; Vogt, Efferson, Berger, \& Fehr, 2015). In order to test the robustness of the watching eyes effect, we conducted two experiments in which participants were exposed to either a photograph of eyes or a geometric pattern while playing a dictator game. We failed to replicate the watching eyes effect in both studies. We report these results to reduce the file drawer problem (i.e., the bias whereby null results remain unpublished; Rosenthal, 1979) in future metaanalyses of this phenomenon (the data of the two studies are available as a supplementary file).

\section{Study 1}

(a) Method

Participants were 33 Japanese undergraduates (24 females and 9 males, mean age $\pm S D=18.39 \pm 0.56$ ), who were recruited from a university-wide participant pool via an email advertisement emphasizing a monetary incentive.

Participants individually played the dictator game in a cubicle. Following Nettle et al.'s (2013) manipulation, we placed an A4-sized poster featuring eyes or a geometric pattern on the wall of the cubicle (Figure 1). The poster consisted of a photograph of male/female eyes or a geometric pattern, along with an irrelevant, distractor, message (No Food or Drink Allowed in the Cubicle), and the logo mark of the university. There were 9, 8, and 16 participants in the male eyes, female eyes, and control conditions, respectively. In the eyes conditions, male and female eyes were cropped from neutral facial expression photographs in the ATR facial expression database (ATR-promotions, 2006). In the control condition, the poster contained a geometric pattern in place of the eyes (a black-and-white geometric pattern was adapted from Gary Andrew Clarke's flickr website: https://www.flickr.com/photos/ilikegraphics/3642920898). In all conditions, the poster was placed slightly to the upper-right of the participants' perspective.

While in the cubicle, participants played a modified version of the one-shot dictator game. Participants received seven coins each worth 100 Japanese yen $(\approx$ US\$0.80), and were instructed to divide the coins between themselves and the subsequent participant (the recipient). This entailed placing the coins in an envelope designated as "For Self," in an envelope designated as "For the Next Participant," or in a combination of both envelopes. Participants were explicitly informed that the experimenter who was interact- 


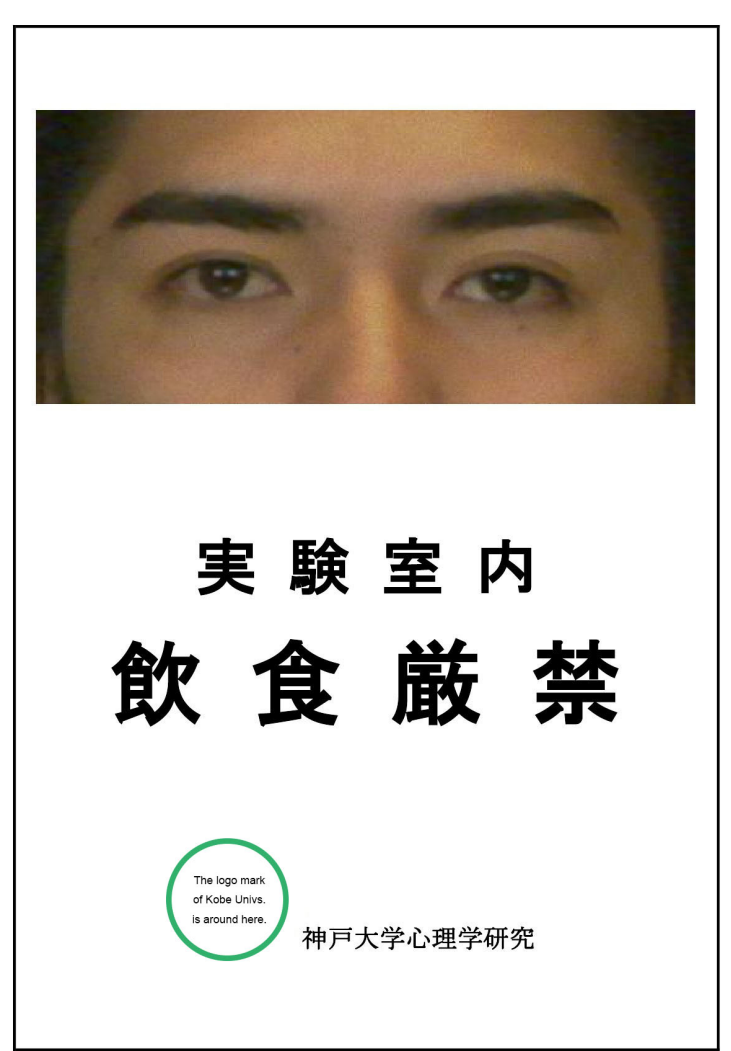

Figure 1. A male-eyes version of the poster used in Study 1.

ing with them would not check how many coins they left for the next participant. Therefore, anonymity was assured in this experiment. Participants were further informed that the previous participant may have left some coins (ranging from 0 to 7) for them, and that their rewards would be the sum of the coins they would take for themselves and the coins left by the previous participant. However, participants were kept uninformed about the number of coins that the previous participant might have left for them until the end of the experiment. After making their allocation decision, participants exited the cubicle with the "For Self" envelope, while leaving the "For the Next Participant" envelope in the cubicle to be handled by another experimenter.

At the end of the experiment, we conducted a funnel debriefing session (Aronson, Wilson, \& Brewer, 1998). In this debriefing session, in addition to explaining the nature of the experiment to participants, we confirmed that no participants had suspected any connection between the poster and the experiment. Finally, participants received the envelope that the previous participant had left for them, were thanked, and dismissed.

\section{(b) Results and discussion}

We first compared the number of coins allocated to subsequent participants between the two eye-image conditions (i.e., male eye-image vs. female eye-image). There was no significant difference: the mean number of coins allocated to the subsequent participant was 1.11 (SD $=1.05)$ in the male eye-image condition and $1.75(S D=$ $1.16)$ in the female eye-image condition, respectively, $t(15)$ $=1.19, p=.25$, Cohen's $d=0.58$. Therefore, we collapsed these two conditions for subsequent analyses.

We then compared the number of coins allocated to subsequent participants between the eye-image condition and the control condition (see Figure $2 \mathrm{a}$ for the distribution of the allocated coins as a function of condition). The difference between the eye-image condition $(M=1.41, S D$ $=1.12)$ and the control condition $(M=1.94, S D=1.34)$ was not significant by an independent samples t-test, $t(31)=$ $1.13, p=.23$, Cohen's $d=0.43$.
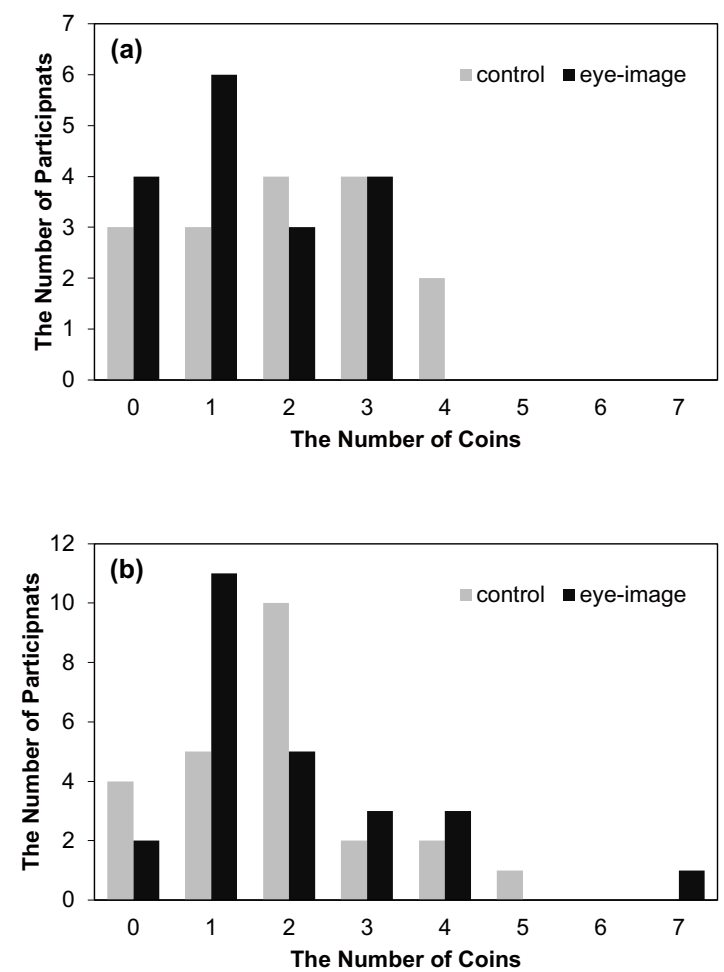

Figure 2. The distribution of the number of coins allocated to the next participant as a function of condition (eye-image vs. control) in Study 1 (a) and Study 2 (b).

Nettle et al. (2013) recommended to analyze the watching eyes effect data as a dichotomous variable (i.e., whether participants gave at least some of the resource to the partner or not) rather than as a continuous variable (i.e., how much money participants allocated to the partner). Therefore, we analyzed the data as a dichotomous variable. However, the proportion of participants who allocated at least one coin to the next participant was not significantly different across the two conditions: $.76(=13 / 17)$ in the eye-image condition and $.81(=13 / 16)$ in the control condition, respectively, $p=1.00$ by Fisher's exact test.

In sum, the watching eyes effect was not observed in Study 1. Retrospectively, the eye-image might not have sufficiently attracted participants' attention while participants made their decisions, as they were probably looking down at the coins on the desk. To avoid this problem, in Study 2, we placed an eye-image on the envelopes disguised as the logo mark of the laboratory.

\section{Study 2}

\section{(a) Method}

Participants were 56 Japanese undergraduates. There were 7 participants who suspected the connection between the eye-image and the experiment. By discarding these 7 participants, 49 participants ( 31 females and 18 males, mean age $\pm S D=19.24 \pm 1.04$ ) were retained for the 
subsequent analyses (there were 12, 13, and 24 participants in the male-eyes, female-eyes, and control conditions, respectively).

The experimental procedure of Study 2 was the same as Study 1 except that the eye-image or the geometric pattern (ostensibly the laboratory's logo mark) was placed on the envelopes. After the experimenter explained the rules of the dictator game, he/she gave participants two envelopes. Participants then anonymously divided the seven coins into the two envelopes.

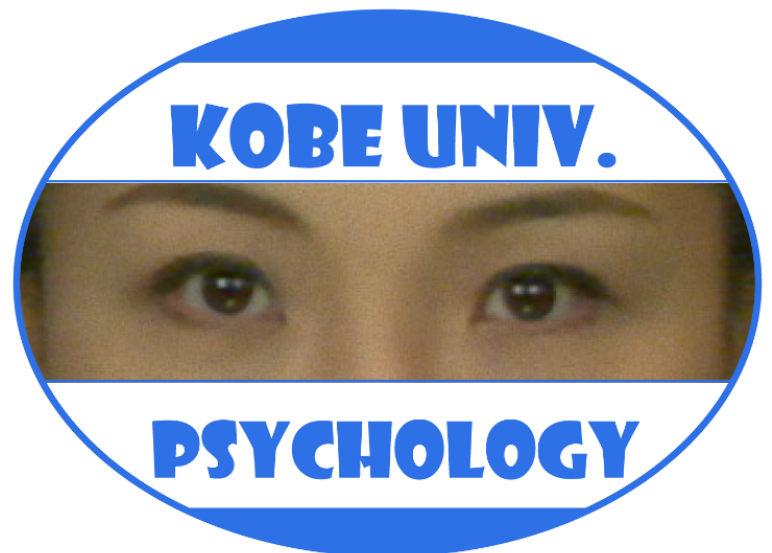

Figure 3. A female-eyes version of the logo mark placed on envelopes in Study 2.

\section{(b) Results}

After confirming that there was no significant difference in the number of coins allocated to subsequent participants between the male-eyes $(2.23, S D=1.96)$ and female-eyes (1.69, $S D=1.11)$ conditions, $t(23)=0.88, p=.39$, Cohen's $d=0.36$, we collapsed these two conditions. The distribution of the number of coins allocated to the next participant as a function of condition (eye-image vs. control) is shown in Figure 2b. The mean number of coins allocated to the next participant was $1.96(S D=1.57)$ in the eye-image condition and $1.83(S D=1.31)$ in the control condition, $t(47)=0.31, p=.76$, Cohen's $d=0.09$. Moreover, the proportion of participants who allocated at least one coin to the next participants was $.83(=20 / 24)$ and $.92(=23 / 25)$ in the control and eye-image conditions, respectively, $p=.42$ by Fisher's exact test. Again, the watching eyes effect was not replicated.

\section{General Discussion}

In this paper, we reported two failed replications of the watching eyes effect. In Study 1, the eye-image or a geometric pattern was presented on the wall as part of a "no food or drink" poster. Due to the null results of Study 1, we suspected that the poster might not have captured participants' attention when they were making the allocation decision. Therefore, in Study 2, we placed eye-images on the very envelopes into which participants allocated coins. Despite this change, the watching eyes effect was also not observed in Study 2.

Two experimental features may have attenuated the watching eyes effect in the present studies. First, the duration of exposure to the eye-image might have been too long in the present studies. Sparks and Barclay (2013) pointed out that the watching eyes effect operates at the non-conscious level, and thus, the subtler the exposure, the stronger the effect (cf. Sparks \& Barclay, 2015). In the present studies, eye-images were presented on the wall or the envelopes throughout the dictator game. Therefore, the prolonged exposure to the eye-image might have nullified the effect. Second, there might have been some ambiguity about what was the desirable behavior in our studies. We asked participants to divide seven coins such that the equality rule does not readily apply (Fehr \& Schmidt, 1999). Moreover, to be fair, participants had to accurately estimate the decision made by the previous participant, who may or may not have left some coins for them. The absence of an unmistakably fair allocation strategy may have attenuated the watching eyes effect.

Since Haley and Fessler's (2005) seminal work, various studies have demonstrated the watching eyes effect. Nonetheless, not all studies succeeded to replicate the effect, and a growing number of authors propose qualifications for this effect (e.g., Nettle et al., 2013; Sparks \& Barclay, 2013; Tane \& Takezawa, 2011). These results along with the present results pose a serious question about the robustness of the watching eyes effect. The altruism-promoting effect of disembodied watching eyes may be weaker than usually believed.

\section{Acknowledgements}

We thank Adam Smith for his helpful comments on earlier drafts. This research was generously supported by the John Templeton Foundation.

\section{References}

Aronson, E., Wilson, T. D., \& Brewer, M. B. (1998). Experimentation in social psychology. In D. Gilbert, S. Fiske, \& G. Lindzey (Eds.), The handbook of social psychology (4th ed., vol. 1), (pp. 99-142). New York: McGraw Hill.

ATR-Promotions (2006). ATR-facial expression database DB99. (http://www.atr-p.com/products/pdf/face-db(J). pdf)

Bateson, M., Nettle, D., \& Roberts, G. (2006). Cues of being watched enhance cooperation in a real-world setting. Biology Letters, 2, 412-414. (doi: 10.1098/ rsbl.2006.0509)

Engelmann, D., \& Fischbacher, U. (2009). Indirect reciprocity and strategic reputation building in an experimental helping game. Games and Economic Behavior, 67, 399-407. (doi: 10.1016/j.geb.2008.12.006)

Fehr, E., \& Schmidt, K. M. (1999). A theory of fairness, competition, and cooperation. Quarterly Journal of Economics, 114, 817-868. (doi: $10.1162 / 003355399556151)$

Fehr, E., \& Schneider, F. (2010). Eyes are on us, but nobody cares: Are eye cues relevant for strong reciprocity? Proceedings of the Royal Society B, 277, 1315-1323. (doi: 10.1098/rspb.2009.1900)

Haley, K. J., \& Fessler, D. M. T. (2005). Nobody's watching? Subtle cues affect generosity in an anonymous economic game. Evolution and Human Behavior, 26, 245-256. (doi: 10.1016/j.evolhumbehav.2005.01.002)

Nettle, D., Harper, Z., Kidson, A., Stone, R., Penton-Voak, I. S., \& Bateson, M. (2013). The watching eyes effect in the Dictator Game: It's not how much you give, it's being seen to give something. Evolution and Hu- 
man Behavior, 34, 35-40. (doi: 10.1016/j.evolhumbehav.2012.08.004)

Nowak, M. A., \& Sigmund, K. (2005). Evolution of indirect reciprocity. Nature, 437, 1291-1298. (doi: 10.1038/ nature04131)

Oda, R., Niwa, Y., Honma, A., \& Hiraishi, K. (2011). An eye-like painting enhances the expectation of a good reputation. Evolution and Human Behavior, 32, 166171. (doi: 10.1016/j.evolhumbehav.2010.11.002)

Raihani, N. J., \& Bshary, R. (2012). A positive effect of flowers rather than eye images in a large-scale, cross-cultural dictator game. Proceedings of the Royal Society B, 279, 3556-3564. (doi: 10.1098/ rspb.2012.0758)

Rosenthal, R. (1979). The file drawer problem and tolerance for null results. Psychological Bulletin, 86, 638641. (doi: 10.1037/0033-2909.86.3.638)

Simpson, B., \& Willer, R. (2008). Altruism and indirect reciprocity: The interaction of person and situation in prosocial behavior. Social Psychology Quarterly, 71, 37-52. (doi: 10.1177/019027250807100106)

Sparks, A., \& Barclay, P. (2013). Eye image increase generosity, but not for long: The limited effect of a false cue. Evolution and Human Behavior, 34, 317-322. (doi: 10.1016/j.evolhumbehav.2013.05.001)

Sparks, A., \& Barclay, P. (2015). No effect on condemnation of short or long exposure to eye images. Letters on Evolutionary Behavioral Science, 6, 13-16. (doi: 10.5178/lebs.2015.35)

Tane, K., \& Takezawa, M. (2011). Perception of human face does not induce cooperation in darkness. Letters on Evolutionary Behavioral Science, 2, 24-27. (doi: 10.5178/lebs.2011.15)

Vogt, S., Efferson, C., Berger, J., \& Fehr, E. (2015). Eye spots do not increase altruism in children. Evolution and Human Behavior, 36, 224-231. (doi: 10.1016/ j.evolhumbehav.2014.11.007)

\section{Correction to Matsugasaki et al. (2015)}

In the article "Two Failed Replications of the Watching Eyes Effect" by K. Matsugasaki, W. Tsukamoto, \& Y. Ohtsubo (Letters on Evolutionary Behavioral Science, 2015, Vol. 6, No. 2, pp. 1720, https://doi.org/10.5178/lebs.2015.36), the results section of Study 2 contained errors. The original version read "the proportion of participants who allocated at least one coin to the next participants was $.83(=20 / 24)$ and $.96(=23 / 25)$ in the eye-image and control conditions, respectively, $p=.42$ by Fisher's exact test" (in the left column of p. 19). This should read "the proportion of participants who allocated at least one coin to the next participants was $.83(=20 / 24)$ and $\underline{.92}(=23 / 25)$ in the control and eye-image conditions, respectively, $p=.42$ by Fisher's exact test.

doi: $10.5178 /$ lebs.2019.69 